\title{
Inequalities in women's health: looking at mortality differentials using an alternative approach
}

\author{
KATH A MOSER, HELENA S PUGH, PETER O GOLDBLATT
}

\begin{abstract}
Data obtained from follow up of the $\mathbf{1 9 7 1}$ census sample in the Office of Population Censuses and Surveys longitudinal study of England and Wales were used to look at women's mortality differentials at ages 15-59. Women were grouped by combining information on marital state, own occupation, husband's occupation (if married), economic activity, and indicators of household wealth (housing tenure and access to a car). Large groups were found with considerable differences in mortality. High mortality was associated with working in manual occupations and living in rented housing with no car in the household. In contrast, low mortality was associated with non-manual occupations and living in owner occupied housing with a car. Among married housewives and single women these extreme groups contributed $44 \%$ of expected deaths, the disadvantaged group experiencing death rates two and a half times that of the advantaged group. Smaller differences were found among married women with an occupational class.

These findings are further evidence of the "health divide" in England and Wales and show that accurately to reflect the relation between a woman's life circumstances and mortality it is necessary to utilise other measures than those based solely on occupation.
\end{abstract}

\section{Introduction}

Traditionally investigators of socioeconomic differentials in mortality have used the Registrar General's classification of social class. ${ }^{12}$ This occupationally based index is particularly problematic when considering women's health and mortality. ${ }^{3-8}$ Alternative measures of socioeconomic state such as housing tenure and access of the household to cars ${ }^{10}$ and overcrowding ${ }^{11}$ have shown wide

Social Statistics Research Unit, City University, London EC1V 0HB

KATH A MOSER, MSC, research fellow

HELENA S PUGH, MSC, research assistant

PETER O GOLDBLATT, MSC, PHD, senior research fellow

Correspondence to: Kath Moser. differences in mortality among women. In this paper we use the longitudinal study of the Office of Population Censuses and Surveys to investigate differentials in mortality among women taking several socioeconomic and demographic measures in combination.

\section{Methods}

Methods used to analyse data from the Office of Population Censuses and Surveys longitudinal study of England and Wales have been detailed elsewhere. ${ }^{9}$ In this paper we look at the relation between all cause mortality in the period 1976-81 among women aged 15-59 at death and their characteristics at the 1971 census. (The relation with specific causes of death will be the subject of a separate report.) Deaths soon after the census were affected by several health selection processes, but these should largely have worn off by 1976-81 enabling us to ascertain the extent of social inequalities in health. ${ }^{1213}$

We analysed single and married women separately (women separated from their husbands were classified as married by the census) but excluded widowed and divorced women. Single women were grouped according to their own social class, their housing tenure, and whether their household had access to a car. For married women their husband's social class was also taken into account. Married women allocated to a social class at census were considered separately from those classified as "unoccupied." Women were allocated to the Registrar General's social classes by using occupational information obtained from census questions asked . . . "in respect of the main employment last week, or of the most recent job if retired or out of work. For persons who have never had a job and for a housewife who did not have a job last week, write 'NONE."' Housewives, those prevented from working by a permanent illness or disability (the "permanently sick"), and most students were classified as "unoccupied."

Standardised mortality ratios were used as summary indices of mortality; approximate $95 \%$ confidence limits were also calculated. ${ }^{14}$ The death rates used for standardisation were those for all women in the longitudinal study irrespective of their marital state.

\section{Results}

Tables I and II show the distribution of expected deaths among single and married women according to their own social class, their husband's social class (for married women), housing tenure, and cars in the household. These data, which indicate the relative size of the different subgroups (weighted by age specific death rates), also illustrate the extent to which the variables were interrelated. For example, among single women most of the expected deaths 
to non-manual workers were to those in owner occupied housing with a car, and most of the expected deaths among manual workers were to those in rented housing with no car.

In the following analysis we have omitted several residual groups whose high mortality was a result of the effects of health selection in order to concentrate on social inequalities in mortality. Specifically, we have having a standardised mortality ratio of 101 . These differences would have been considerably wider had residual groups been included.

Table III shows univariate mortality differentials for each of the three groups of women. In the case of single women each characteristic divided the population into large groups with widely different mortality. Low mortality was associated with non-manual occupations, owner occupied housing, and

TABLE I-Percentage distribution of expected deaths 1976-81 among single women aged 15-59 at death by own social class, cars in household, and housing tenure. (No of expected deaths $=162 \cdot 0$ )

\begin{tabular}{|c|c|c|c|c|c|c|}
\hline \multirow[b]{2}{*}{ Own social class } & \multicolumn{2}{|c|}{$\operatorname{Car}(\mathrm{s})$} & \multicolumn{2}{|c|}{ No car } & \multirow[b]{2}{*}{ Institutions } & \multirow[b]{2}{*}{ All } \\
\hline & Owner occupied & Rented & Owner occupied & Rented & & \\
\hline $\begin{array}{l}\text { Non-manual } \\
\text { Manual } \\
\text { "Unoccupied" etc }\end{array}$ & $\begin{array}{r}17 \cdot 8 \\
3 \cdot 4 \\
6 \cdot 2\end{array}$ & $\begin{array}{l}9 \cdot 1 \\
3 \cdot 9 \\
3 \cdot 2\end{array}$ & $\begin{array}{l}9 \cdot 6 \\
4 \cdot 2 \\
2 \cdot 9\end{array}$ & $\begin{array}{r}13 \cdot 8 \\
12 \cdot 4 \\
6 \cdot 7\end{array}$ & $\begin{array}{l}2 \cdot 4 \\
1 \cdot 0 \\
3 \cdot 2\end{array}$ & $\begin{array}{l}52 \cdot 7 \\
24 \cdot 9 \\
22 \cdot 2\end{array}$ \\
\hline All & $27 \cdot 3$ & $16 \cdot 2$ & $16 \cdot 7$ & $32 \cdot 8$ & 6.9 & $100 \cdot 0$ \\
\hline
\end{tabular}

$\star 11.7 \%$ Of expected deaths in this group were to women with inadequately described occupations or in armed forces.

Discrepancies in some totals due to rounding errors.

TABLE II-Percentage distribution of expected deaths 1976-81 among married women aged 15-59 at death by own and husband's social class, cars in household, and housing tenure. (No of expected deaths $=1300 \cdot 8)$

\begin{tabular}{|c|c|c|c|c|c|c|c|c|c|c|c|c|c|c|}
\hline \multirow[b]{5}{*}{ Own social class } & \multicolumn{14}{|c|}{ Husband's social class } \\
\hline & \multicolumn{6}{|c|}{ Non-manual } & \multicolumn{6}{|c|}{ Manual } & \multirow[t]{4}{*}{ Othert } & \multirow[t]{4}{*}{ All } \\
\hline & \multirow[b]{3}{*}{$\begin{array}{c}\text { Owner } \\
\text { occupied }\end{array}$} & \multicolumn{2}{|l|}{$\operatorname{Car}(s)$} & \multicolumn{3}{|c|}{ No car } & \multicolumn{3}{|c|}{$\operatorname{Car}(\mathrm{s})$} & \multicolumn{3}{|c|}{ No car } & & \\
\hline & & \multicolumn{2}{|c|}{ Rented } & \multirow[b]{2}{*}{$\begin{array}{c}\text { Owner } \\
\text { occupied }\end{array}$} & \multicolumn{2}{|c|}{ Rented } & \multicolumn{3}{|c|}{ Rented } & \multirow[b]{2}{*}{$\begin{array}{c}\text { Owner } \\
\text { occupied }\end{array}$} & \multicolumn{2}{|c|}{ Rented } & & \\
\hline & & Private & $\begin{array}{c}\text { Local } \\
\text { authority }\end{array}$ & & Private & $\begin{array}{c}\text { Local } \\
\text { authority }\end{array}$ & $\begin{array}{c}\text { Owner } \\
\text { occupied }\end{array}$ & Private & $\begin{array}{c}\text { Local } \\
\text { authority }\end{array}$ & & Private & $\begin{array}{c}\text { Local } \\
\text { authority }\end{array}$ & & \\
\hline $\begin{array}{l}\text { Non-manual } \\
\text { Manual } \\
\text { "Unoccupied" }\end{array}$ & $\begin{array}{r}9 \cdot 9 \\
2 \cdot 1 \\
12 \cdot 2\end{array}$ & $\begin{array}{l}1.5 \\
0.5 \\
1.5\end{array}$ & $\begin{array}{l}1 \cdot 1 \\
0 \cdot 9 \\
1 \cdot 1\end{array}$ & $\begin{array}{l}0.7 \\
0.3 \\
1 \cdot 1\end{array}$ & $\begin{array}{l}0 \cdot 4 \\
0 \cdot 2 \\
0 \cdot 3\end{array}$ & $\begin{array}{l}0 \cdot 3 \\
0 \cdot 4 \\
0 \cdot 5\end{array}$ & $\begin{array}{l}5 \cdot 2 \\
4 \cdot 7 \\
7 \cdot 4\end{array}$ & $\begin{array}{l}1 \cdot 0 \\
1 \cdot 3 \\
1 \cdot 8\end{array}$ & $\begin{array}{l}2 \cdot 6 \\
5 \cdot 6 \\
5 \cdot 0\end{array}$ & $\begin{array}{l}1 \cdot 1 \\
2 \cdot 2 \\
3 \cdot 0\end{array}$ & $\begin{array}{l}0.5 \\
1.2 \\
1.6\end{array}$ & $\begin{array}{l}1 \cdot 3 \\
5 \cdot 1 \\
5 \cdot 4\end{array}$ & $\begin{array}{l}1 \cdot 6 \\
1 \cdot 7 \\
3 \cdot 0\end{array}$ & $\begin{array}{l}27 \cdot 3 \\
26 \cdot 2 \\
44 \cdot 0\end{array}$ \\
\hline All* & $24 \cdot 7$ & 3.5 & $3 \cdot 2$ & $2 \cdot 2$ & 1.0 & $1 \cdot 2$ & $17 \cdot 7$ & $4 \cdot 2$ & $13 \cdot 6$ & 6.6 & 3.4 & $12 \cdot 2$ & $6 \cdot 7$ & $100 \cdot 0$ \\
\hline
\end{tabular}

^Figures in body of table exclude $2 \cdot 6 \%$ of expected deaths among women with inadequately described occupations or in armed forces.

t"Other" includes women enumerated in institutions or whose husbands were "unoccupied," in armed forces, or had inadequately described occupations or for whom there was no information.

TABLE III-Mortality among single and married women aged 15-59 at death, 1976-81. (Numbers of observed deaths given in parentheses)

\begin{tabular}{|c|c|c|c|c|c|c|}
\hline & \multicolumn{2}{|c|}{ Single women } & \multicolumn{4}{|c|}{ Married women } \\
\hline & $\begin{array}{c}\text { Standardised } \\
\text { mortality ratio }\end{array}$ & $\begin{array}{c}95 \% \\
\text { Confidence interval }\end{array}$ & $\begin{array}{c}\text { Standardised } \\
\text { mortality ratio }\end{array}$ & $\begin{array}{c}95 \% \\
\text { Confidence interval }\end{array}$ & $\begin{array}{c}\text { Standardised } \\
\text { mortality ratio }\end{array}$ & $\begin{array}{c}95 \% \\
\text { Confidence interva }\end{array}$ \\
\hline \multicolumn{7}{|l|}{ Own social class: } \\
\hline Non-manual & $84(68)$ & $65-105$ & $79(262)$ & $69-89$ & - & - \\
\hline Manual & $160(62)$ & 122.203 & $97(310)$ & $87-109$ & - & - \\
\hline Manual & - & - & $96(400)$ & $87-106$ & $121(383)$ & 109-134 \\
\hline \multicolumn{7}{|l|}{ Housing tenure: } \\
\hline Owner occupied & $85(48)$ & $62-111$ & $79(269)$ & $69-88$ & $84(258)$ & 74-94 \\
\hline Privately rented & & & $93(79)$ & $73-115$ & $111(75)$ & $87-138$ \\
\hline Local authority rented & $129(82)$ & $102-159$ & $99(223)$ & $86-113$ & $130(203)$ & $112-148$ \\
\hline \multicolumn{7}{|l|}{$\begin{array}{l}\text { Cars in household: } \\
\end{array}$} \\
\hline $\operatorname{Car}(\mathrm{s})$ & $80(44)$ & $57-105$ & $83(394)$ & $75-92$ & $83(312)$ & $74-92$ \\
\hline
\end{tabular}

Discrepancies in some totals due to non-response.

excluded women enumerated in institutions (a group which includes hospital patients), single women for whom we had no occupational information (mainly students but whose mortality was dominated by that of the permanently sick and disabled), and married women whose husbands either could not be assigned an occupational class or for whom there was no information.

Single women had raised mortality with a standardised mortality ratio of 108. Married women as a whole had low mortality with a standardised mortality ratio of 94 ; those assigned an occupational class had the lowest mortality (standardised mortality ratio 88 ), "unoccupied" married women having a car; conversely, high mortality was associated with manual occupations, rented accommodation, and no car. Among married women with an occupational class there were also clear mortality differentials in respect of each characteristic but they were much narrower than for single women. Differentials by housing tenure and access to a car among unoccupied married women were very similar to those found among single women; the differential in respect of husband's occupation, however, was narrower than that found by own occupation among single women.

By cross classifying women using all these variables we examined whether wider and more finely differentiated gradients might be identified. 


\section{SINGLE WOMEN}

The comparatively small number of deaths among single women did not allow for a satisfactory three way analysis by occupation, tenure, and access to cars. Nevertheless, both the distribution of expected deaths (table I) and unpublished work suggested that, having taken access to a car into account, housing tenure contributed little; we thus focused on occupation and access to cars.

Figure 1 shows the importance of cross classifying among single women, an extremely wide range of standardised mortality ratios (from 69 to 178) being found in large subgroups. Neither classification was as effective on its

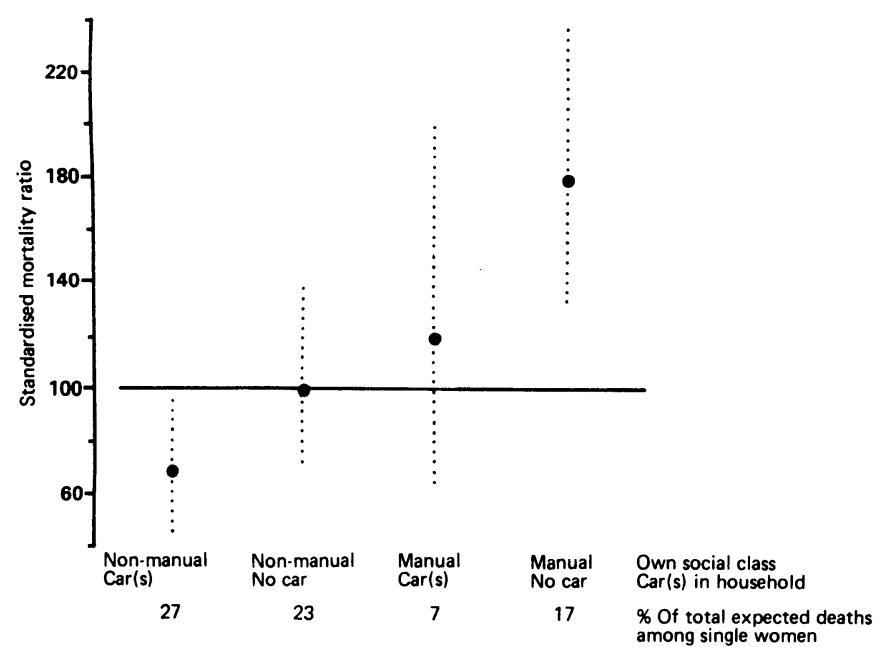

FIG 1-Mortality among single women aged 15-59 at death, 1976-81. Points are standardised mortality ratios and $95 \%$ confidence intervals.

own because access to a car differentiated between the large proportion in non-manual jobs, whereas occupation subdivided the heterogeneous group with no access to a car. Single women in households with a car and in nonmanual jobs stood out as having the lowest mortality, whereas exceptionally high mortality was found among those in manual jobs and living in households without access to a car. Both groups were large.

\section{MARRIED WOMEN}

Women assigned an occupational class were principally those in paid employment during the week preceding census day 1971 . Figure 2 shows the main groups in terms of numbers of expected deaths; their standardised mortality ratios ranged from 70 to 113 . At the lowest extreme were women whose own occupational class and that of their husbands were non-manual, who lived in owner occupied housing, and who had a car. The highest standardised mortality ratio was for women whose own and their husband's occupational classes were manual, who lived in rented housing, and who had no car. This analysis strongly suggested that cross classification by all four

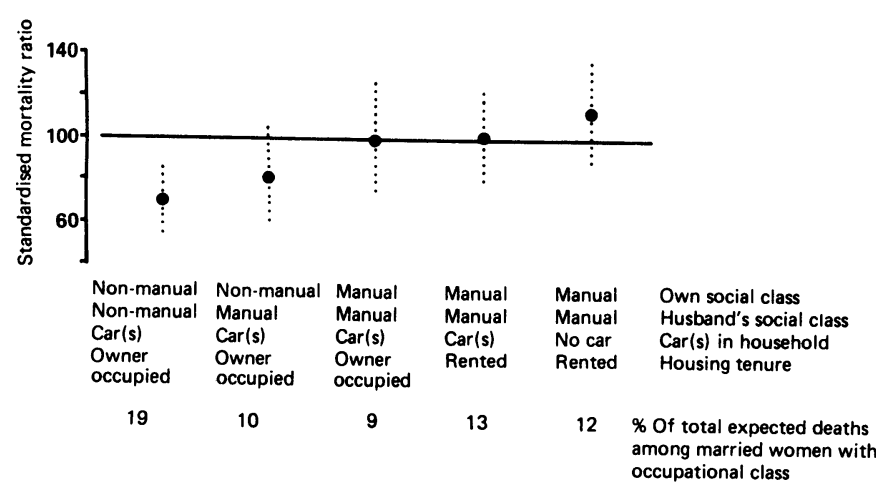

FIG 2-Mortality among married women with an occupational class aged 15-59 at death, 1976-81. Points are standardised mortality ratios and $95 \%$ confidence intervals. variables was worth while. Most married women assigned an occupational class were in households with a car, but mortality levels within this group were clearly heterogeneous. Most lived in owner occupied accommodation, but by using the women's own and their husband's occupational class we could further discriminate their mortality; the lowest standardised mortality ratio (70) was found where the woman and her husband both had nonmanual jobs and the highest standardised mortality ratio (99) where both had manual jobs. Conversely, among women in rented housing, where both partners were in manual occupations, information on cars distinguished two groups with different death rates-standardised mortality ratio 101 with access to a car; standardised mortality ratio 113 with no access to a car.

Married women classified as "unoccupied" had standardised mortality ratios ranging from 65 to 161 (fig 3 ). The largest group was that with the lowest mortality and having all the "advantageous" characteristics. The four remaining groups comprised women with husbands in manual occupations, among whom there was still considerable variation in standardised mortality ratios. Information on housing tenure and cars enabled us further to differentiate, each characteristic providing an additional level of discrimination.

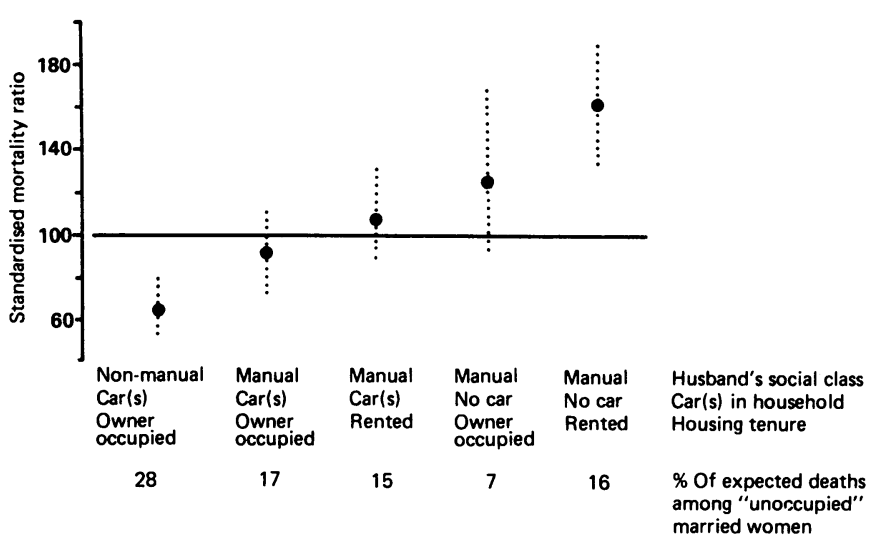

FIG 3-Mortality among "unoccupied" married women aged 15-59 at death, 1976-81. Points are standardised mortality ratios and $95 \%$ confidence intervals.

\section{Discussion}

We have found considerable differences in mortality among women. Table IV summarises the extent of these differentials and the characteristics that best describe them. As the lives, employment patterns, and domestic responsibilities of single and married women are very different, we have considered their mortality separately; the methods, however, allow direct comparisons between them.

For single women and married "unoccupied" women mortality differentials were extremely large. In both cases the differential was of a similar order of magnitude; for every 100 deaths in the low mortality group there were about 250 deaths in the high mortality group after having accounted for any differences in age structures.

In the case of single women the main group with low mortality was those with the most favourable social circumstances (nonmanual workers living in a household with a car). Conversely, the group who had none of these "advantageous" characteristics had very high mortality. As these two groups together accounted for $44 \%$ of the deaths expected among single women, they represent a large and important component of the single population. These differentials were found across the age range.

Among "unoccupied" married women the size of the differential between the largest contrasting groups was similar to that of single women. Though this group included the permanently sick, there were not enough deaths to affect our conclusions. In comparison with these exceptionally large differentials in mortality those found among married women with an occupational class were small. This differential, however, was found among a group of women whose characteristics pointed to initial good health at census: they were married; they were assigned a social class, as were their husbands; and they lived in private households.

High mortality was associated with working in manual occupa- 
TABLE IV—Summary of results

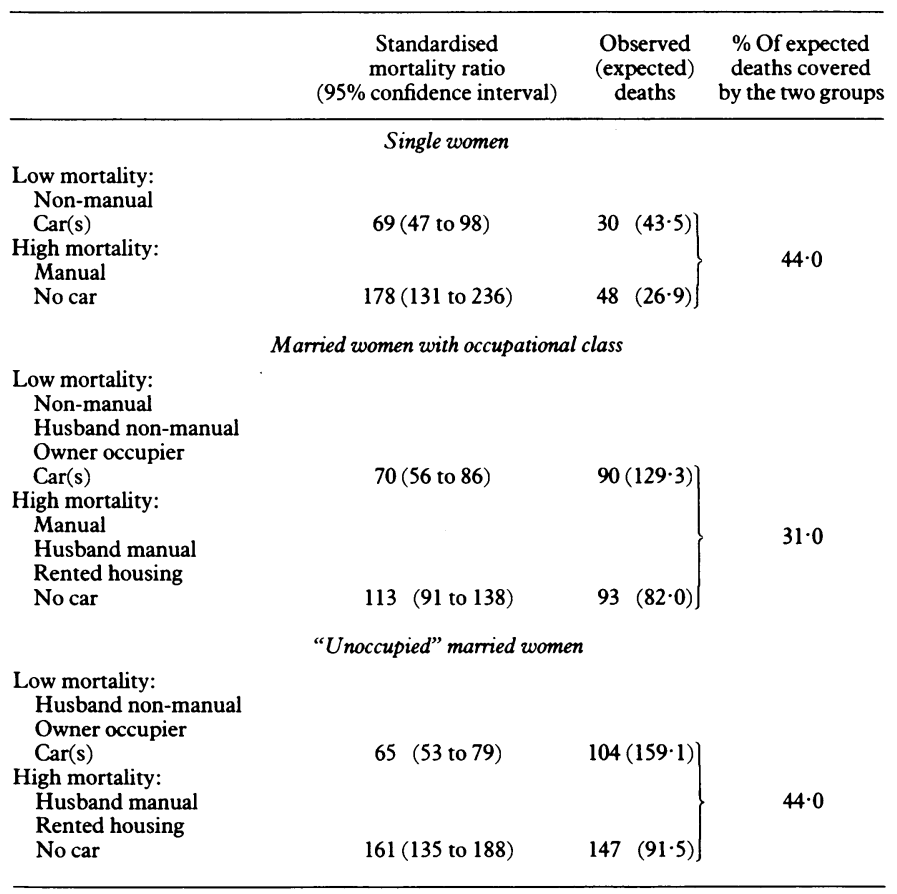

tions and living in rented housing with no access to a car in the household. In contrast, low mortality was associated with nonmanual occupations and living in owner occupied housing with access to a car. In each case these characteristics may be ordered to highlight a mortality gradient which includes several large groups. Of particular note, the two groups at the extremes of this range accounted for a considerable proportion of the expected deaths.

The differences reported here are based on census measures which distinguish relative levels of advantage and disadvantage. Thus though possession of specific attributes described by these variables may directly affect mortality, it is primarily their value as effective descriptors of relative household wealth or poverty which appears to lie behind the wide and consistent gradients found.

Table IV shows very little difference among the standardised mortality ratios of the low mortality groups. In contrast, among the high mortality groups married women with an occupational class did not appear to have the extreme disadvantage evident among single women or "unoccupied" married women. This may suggest a positive effect of having two earners in the household.

The use of generalised linear modelling techniques ${ }^{15}$ in a separate analysis highlighted the arguments for examining separately the mortality of single women, married women with an occupational class, and unoccupied married women. ${ }^{16}$ For single women access to cars and own occupational class emerged as important and independent predictors of mortality; among married women with an occupational class the relatively small amount of variation may best be described using husband's class, whereas differences among unoccupied married women are characterised by a relation between access to cars and husband's class. The importance of each of the characteristics discussed in this paper is thus confirmed.

\section{Conclusion}

Many of the relations identified derive from simple empirical observations, such as the notion that the financial wellbeing and security associated with access to a car and home ownership are more commonly found among those in non-manual occupations. The value of the analysis presented here has been to show how these inherent links may be exploited in the study of health differences. By using several simple measures of socioeconomic state in combination comparatively large groups may be constructed producing greater heterogeneity in mortality than can be achieved using, for example, a finer differentiation of any one measure.

The differences in women's mortality identified here provide further evidence of the health divide in England and Wales ${ }^{17}$ and show that to accurately reflect the relation between a woman's life circumstances and mortality it is necessary to utilise other measures than those based solely on occupation.

Though our analysis makes an important step towards adequately characterising these circumstances, there are other important factors we have not included. We plan to extend our work by incorporating information on whether a woman is working full time or part time; on her fertility behaviour; and on the presence or absence of dependent children or relatives in the household. In particular, we intend to make use of a composite social classification scheme for women which is currently being developed by colleagues at City University. ${ }^{18}$ We shall also be examining mortality after 1981 in the longitudinal study according to information collected at both the 1971 and 1981 censuses.

These analyses are part of a review by members of the Social Statistics Research Unit, City University, of mortality data available from the Office of Population Censuses and Surveys longitudinal study. This programme is supported by a grant from the Medical Research Council. The views expressed are ours alone. We thank Mickey Rosato for all his work on computing for this project and members of this unit, especially Helen Roberts, for helpful advice and suggestions.

We thank the Controller of HMSO for permission to publish this report. Crown copyright is reserved.

\section{References}

1 Registrar General. Occupational montality 1970-72. Decennial supplement. London: HMSO, 1978. (Series DS No 1.)

2 Registrar General. Occupational mortality 1979-80, 1982-83. Decennial supplement. London: HMSO, 1986.

3 MacFarlane A. Official statistics and women's health and illness. Equal Opportunities Commission Research Bulletin 1980;No 4:43-77.

4 McDowall M. Measuring women's occupational mortality. Population Trends 1983;34:25-9.

5 Roman E, Beral V, Inskip H. Occupational mortality among women in England and Wales. BrMed f 1985;291:194-6.

6 Arber S. Social class, non-employment, and chronic illness: continuing the inequalities in health debate. Br Med F 1987;294:1069-73.

7 Mitchell J. What is to be done about illness and health? Crisis in the eighties. London: Penguin Books, 1984.

8 Moser KA, Pugh HS, Goldblatt PO. Inequalities in women's health: developing an alernative approach. London: City University, 1987. (Social Statistics Research Unit working paper No 54.)

9 Fox AJ, Goldblatt PO. Socio-demographic mortality differentials: longitudinal study 1971-75. London: HMSO, 1982. (Series LS No 1.)

10 Moser KA, Goldblatt PO. Mortality of women in the OPCS longitudinal study; differentials by own occupation and household and housing characteristics. London: City University, 1985. (Social Statistics Research Unit working paper No 26.)

11 Alexander F, O'Brien F, Hepburn W, Miller M. Association between mortality among women and socioeconomic factors in general practices in Edinburgh: an application of small area

statistics. $B r M e d \mathcal{F} 1987 ; 295: 754-6$.
12 Fox AJ, Goldblatt PO, Adelstein AM. Selection and mortality differentials. $\mathcal{f}$ Epidemiol Community Health 1982;36:69-79.

13 Fox AJ, Goldblatt PO, Jones DR. Social class mortality differentials: artefact, selection or life circumstances? F Epidemiol Community Health 1985;39:1-8.

14 Vandenbroucke JP. A short-cut method for calculating the 95 per cent confidence interval of the standardised mortality ratio. $A m \mathcal{F}$ Epidemiol 1982;115:303-4.

15 McCullagh P, Nelder JA. Generalized linear models. London: Chapman and Hall, 1983.

16 Goldblatt PO. Mortality differences at working ages: the use of generalised linear models to compare measures. London: City University, 1987. (Social Statistics Research Unit working paper mo 53.)

17 Whitehead M. The health divide: inequalities in health in the 1980's. London: Health Education Council, 1987.

18 Roberts H, Barker R. The social classification of women. London: City University, 1986. (Social Statistics Research Unit working paper No 46.)

(Accepted 23 December 1987) 